\title{
Topological algorithm to form power of compensating devices of distribution networks
}

\author{
Dauren S. Akhmetbayev ${ }^{1, *}$, Abdigali R. Dzhandigulov ${ }^{2}$, and Ansar Berdygozhin ${ }^{3}$ \\ ${ }^{1}$ Kazakh Agrotechnical University, Electric Power Supply Department, Nur-Sultan, Kazakhstan \\ ${ }^{2}$ Eurasian National University, Algebra and Geometry Department, Nur-Sultan, Kazakhstan \\ ${ }^{3}$ The University of Strathclyde, PhD student of Electronic and Electrical Engineering Department, United Kingdom
}

\begin{abstract}
Effectiveness of providing consumers with technical limits of voltage deviation relates with integrating digital technologies in automation voltage regulation control. Automatized compensating devices, intended control voltage, tunes without consideration of influence of other compensating devices installed for the same purpose. It leads to their energetical efficiency deterioration. Thus, there is a need to develop new algorithms needed power of compensating devices.
\end{abstract}

\section{Introduction}

Compensation of reactive power in distribution networks extends to all power consumers and is mandatory for all power supply organizations regardless of their departmental affiliation [1]. It is known that the transfer of reactive power from the $6-35 \mathrm{kV}$ network to the lowvoltage network, as a rule, is economically unprofitable. Continuous control of compensating device modes is required in order to provide standard parameters of electric power quality, which is associated with great difficulties due to mutual influence and variety of their modes. The most practical and theoretical importance is the development of new methods for controlling the reactive power of compensating devices of distribution networks [2]. Voltages at different points of distribution networks vary and depend on network parameters and flow distribution mode. Voltage deviation from nominal values in distribution networks is limited by quantitative values of electromagnetic compatibility $[3,4]$. Stringent requirements for maintaining voltage within technically defined limits necessitate its automatic control. One of the main methods of voltage control in electrical networks is the use of compensating devices at lowering substations operating on the principle of voltage stabilization $[5,6]$. In order to increase the efficiency of compensating devices, it is necessary to determine the conditions of the adequacy of the control range of reactive power to ensure the desired voltage level on the substation low-voltage buses in the mode of greatest loads. This problem is solved in a traditional way individually for each load node based on the results of calculating the steady-state mode of electric networks of power systems. The solution of this problem is directly related to conditions of reactive power balance of the given unit. The installation of a compensating device at an arbitrary point in the network leads to the redistribution of reactive power over the distribution network as a whole. Achieving the desired voltage level at the same time becomes a rather difficult task. Therefore, the development of a systematic method for determining the required reactive power of compensating devices is an urgent task in the conditions of the digitalization of voltage control in electrical networks.

\section{Topological equations of node voltages}

Topological models of node voltages allow you to define mode parameters based on natural parameters and node loads of the network [7]. In work [8] the method of calculation of system function of resistance with application of coefficients of distribution of setting currents determined on the basis of the topology of the electric network is developed. Developed algorithms are implemented in the form of software complex of search and determination of all possible and specific trees of a directed graph of the complex electrical network $[9,10]$. The distribution coefficients of the setting currents are formalized based on the topological expression [7]:

$$
\underline{C}_{i j}=\frac{\sum F_{i j}}{\sum F}
$$

where $\sum F_{i j}$ - the algebraic sum of specific i-branch trees relative to the $\mathrm{j}$-th node;

$\sum F$ - an arithmetic sum of all possible graph trees.

Node voltages are determined by topological expression obtained by analytical transformation of known equations of electric state of networks [13-16]:

* Corresponding author: axmetbaev46@mail.ru 


$$
\dot{U}=\dot{U}_{0}-\underline{C}^{t} \underline{Z}_{\partial} \underline{C}_{\hat{U}^{-1}} \hat{S}^{-}
$$

where $\underline{C}$ - matrix of complex coefficients of assignment currents distribution; $\underline{Z}_{\partial}$ - matrix of complex coefficients of assignment currents distribution; $\dot{U}_{0}$ - base node voltage; $\hat{U}_{\partial}$ - diagonal matrix of a conjugated complex of node voltages; $\hat{S}$ - vector of a conjugated complex of nodal loads; $\boldsymbol{t}$ - sign of matrix transposition.

\section{Modelling of compensating devices power}

As is known, calculations of stationary modes of electric networks are accompanied by determination of the required capacities of compensating devices, which provide the desired voltage on the buses of secondary windings of transformers $[2,5]$. This made it possible to formulate the task of modelling the power of compensating devices from the position of synthesis of the permissible mode on the voltage of electric networks. Solution of this problem is achieved by conversion of topological equation (2) relative to power of compensating devices.

Suppose that the provision of the required voltage is achieved by switching on static capacitors on the buses of the low voltage winding of the transformer. Therefore, the desired voltage values on the downshift buses can be considered a predetermined value. Then, it is necessary to find the power of the compensating devices installed to provide the desired node voltage.

The analytical relationship between the power of the compensating devices and the mode and network parameters can be established based on the transformation of equation (2).

Consider a complex power grid where the desired node voltage value is provided by adjusting the power of the compensating devices. Then equation (2) is written as:

$$
\underline{\dot{U}}_{i d}=\underline{\dot{U}}_{0}+\sum_{j=1}^{n} \sum_{k=1}^{m} \underline{C}_{i k}^{t} \underline{Z}_{k} \underline{C}_{k j} \underline{\dot{U}}_{j d}^{-1}\left(\underline{\dot{S}}_{j}-i Q K_{j}\right)
$$

where $\dot{U}_{i d}$ - complex desired voltage value of the i-th node; $Q K_{j}$ - power of compensating device of $\mathrm{j}$-th node.

Equation (3) with respect to the real and imaginary part is written as follows:

$$
\begin{aligned}
& \omega_{\underline{U}_{i}^{\prime}}(\delta, Q K)=-U_{i d} \cos \delta_{i}+U_{0}+ \\
& +\sum_{j=1}^{n} U_{\Delta i j} \cos \left(\delta_{j}-\varphi_{j}+\psi_{i j}\right)+ \\
& +\sum_{j=1}^{n} \underline{Z}_{i j} U_{j d}^{-1} Q K_{j} \sin \left(\delta_{j}+\psi_{i j}\right),
\end{aligned}
$$

$$
\begin{aligned}
& \omega_{\underline{U}_{i}^{\prime \prime}}(\delta, Q K)=-U_{i d} \sin \delta_{i}+ \\
& +\sum_{j=1}^{n} U_{\Delta i j} \sin \left(\delta_{j}-\varphi_{j}+\psi_{i j}\right)-
\end{aligned}
$$

$-\sum_{j=1}^{n} \underline{Z}_{i j} U_{j d}^{-1} Q K_{j} \cos \left(\delta_{j}+\psi_{i j}\right)$,

where

$$
\underline{Z}_{i j}=\sqrt{\left(\operatorname{Re} \sum_{j=1}^{m} \underline{C}_{i k}{ }^{t} \underline{Z}_{j} \underline{C}_{j j}\right)^{2}+\left(\operatorname{Im} \sum_{j=1}^{m} \underline{C}_{i k}{ }^{t} \underline{Z}_{j} \underline{C}_{j j}\right)^{2}}
$$

- mutual system function resistance module;

$$
U_{\Delta i j}=\underline{Z}_{i j} U_{j d}^{-1} \sqrt{P_{j}^{2}+Q_{j}^{2}}
$$

- module of the partial node voltage drop of the i-th node;

$U_{i d}$ - desired voltage of i-th node ;

$P_{j}, Q_{j}$ - active and reactive power of $\mathrm{i}$-th node ;

$U_{i}^{\prime}, U_{i}^{\prime \prime}$ - real and imaginary parts of complex voltage of i-th node ;

It can be seen from (4) and (5) that for a complex circuit of an electric network consisting of $\mathrm{n}$ independent nodes, a system of $2 n$ equations with $2 n$ unknowns is composed, which can be solved by the Newton method.

If we neglect the influence of the phases of the node voltages on the values of the driving currents, then the calculated expressions for the partial derivatives of the Jacobi matrix are simplified since the equations of the balance of the real and imaginary parts of the voltage of the i-th node are written in the form:

$$
\begin{aligned}
& \partial \omega_{v_{i}^{\prime}}(\delta, Q K)=-U_{i \varkappa} \sin \delta_{i}+U_{0}+ \\
& +\sum_{j=1}^{n} U_{\Delta i j} \cos \left(-\varphi_{j}+\psi_{i j}\right)+ \\
& +\sum_{j=1}^{n} \underline{Z}_{i j} U_{j \varkappa}^{-1} Q K_{j} \sin \psi_{i j}=0
\end{aligned}
$$




$$
\begin{aligned}
& \partial \omega_{v_{i}^{\prime \prime}}(\delta, Q)=-U_{i \varkappa} \sin \delta_{i}+ \\
& +\sum_{j=1}^{n} U_{\Delta i j} \sin \left(-\varphi_{j}+\psi_{i j}\right)- \\
& -\sum_{j=1}^{n} \underline{Z}_{i j} U_{j \varkappa}^{-1} Q K_{j} \cos \psi_{i j}=0 .
\end{aligned}
$$

The following expressions are valid for Jacobi matrix elements:

$$
\begin{aligned}
& \frac{\partial \omega_{v^{\prime}}(\delta, Q K)}{\partial \delta}=U_{i d} \sin \delta_{i} \\
& \frac{\partial \omega_{v^{\prime}}(\delta, Q K)}{\partial Q K}=\sum_{j=1}^{n} \underline{Z}_{i j} U_{j d}^{-1} Q K_{j} \sin \psi_{i j} ; \\
& \frac{\partial \omega_{v^{\prime \prime}}(\delta, Q K)}{\partial \delta}=-U_{i d} \cos \delta_{i} ; \\
& \frac{\partial \omega_{v^{\prime \prime}}(\delta, Q K)}{\partial Q K}=-\sum_{j=1}^{n} \underline{Z}_{i j} U_{j d}^{-1} Q K_{j} \cos \psi_{i j} .
\end{aligned}
$$

When calculating distribution networks, the voltage of the $\mathrm{i}$-th node is described by the equation of the form:

$$
\begin{aligned}
& \omega_{\underline{U}_{i}}(Q K)=-U_{i d}+U_{0}+ \\
& +\sum_{j=1}^{n} U_{\Delta i j} \cos \left(-\varphi_{j}+\psi_{i j}\right)+ \\
& +\sum_{j=1}^{n} \underline{Z}_{i j} U_{j d}^{-1} Q K_{j} \sin \psi_{i j}=0
\end{aligned}
$$

It can be seen from (8) that the compensating devices' powers are determined by solving a system of $n$ linear equations.

Based on providing the desired node voltage at a known value prior to reactive power compensation, the system of equations for calculating power of the compensating device can be written as:

$$
\omega_{\underline{U}_{i}}(Q K)=-U_{i \varkappa c}+U_{i}+\sum_{j=1}^{n} \underline{Z}_{i j} U_{i \varkappa c}^{-1} Q K_{j} \sin \psi_{i j}=0
$$

To calculate the simplest scheme, equation (9) is easily converted into a known expression:

$$
Q K=\frac{U_{d}-U}{X} U_{d}
$$

where $X=\underline{Z} \sin \psi \quad$ - the reactance of the network;

$U$ - unit voltage value before reactive power compensation;
$U_{d}$ - value of the desired node voltage after switching on the compensating device with power.

\section{Example of compensating device power calculation}

As an example, the calculation of the required compensating device capacity for the section of the real $10 \mathrm{kV}$ "Valikhanov" distribution network, shown in Fig. 1 , is given.

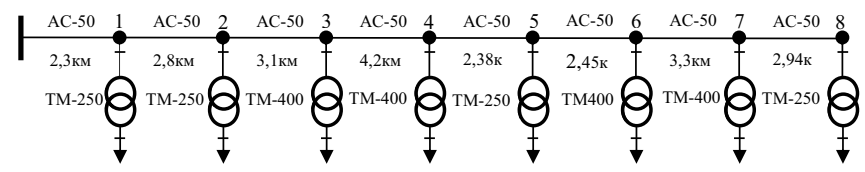

Fig. 1. $10 \mathrm{kV}$ "Valikhanov" distribution network.

The settlement scheme is submitted in fig. 2 .

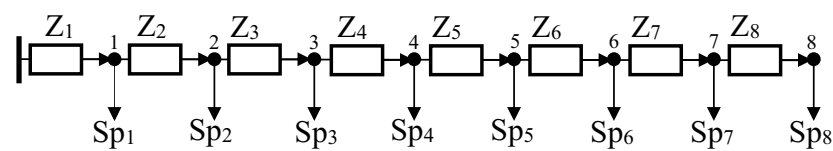

Fig. 2. Computational scheme.

The parameters required to perform the calculations are presented in matrix form:

$$
Z_{b}=\left[\begin{array}{l}
1.368+j 0.902 \\
1.666+j 1.098 \\
1.845+j 1.215 \\
2.499+j 1.646 \\
1.416+j 0.933 \\
1.458+j 0.96 \\
1.963+j 1.294 \\
1.749+j 1.152
\end{array}\right] \text { Ohm }
$$

$$
S=\left[\begin{array}{c}
S_{p 1} \\
S_{p 2} \\
S_{p 3} \\
S_{p 4} \\
S_{p 5} \\
S_{p 6} \\
S_{p 7} \\
S_{p 8}
\end{array}\right]=\left[\begin{array}{l}
0.123+j 0.034 \\
0.12+j 0.031 \\
0.189+j 0.042 \\
0.185+j 0.052 \\
0.111+j 0.037 \\
0.184+j 0.057 \\
0.193+j 0.047 \\
0.126+j 0.031
\end{array}\right] \mathrm{MVA}
$$


distribution coefficients of node currents

$$
\mathrm{C}=\mathrm{M}^{-1}=\left[\begin{array}{cccccccc}
-1 & -1 & -1 & -1 & -1 & -1 & -1 & -1 \\
0 & -1 & -1 & -1 & -1 & -1 & -1 & -1 \\
0 & 0 & -1 & -1 & -1 & -1 & -1 & -1 \\
0 & 0 & 0 & -1 & -1 & -1 & -1 & -1 \\
0 & 0 & 0 & 0 & -1 & -1 & -1 & -1 \\
0 & 0 & 0 & 0 & 0 & -1 & -1 & -1 \\
0 & 0 & 0 & 0 & 0 & 0 & -1 & -1 \\
0 & 0 & 0 & 0 & 0 & 0 & 0 & -1
\end{array}\right]
$$

Taking $\mathrm{U}_{0}=10.5 \mathrm{kV}$, we determine the node voltages by formula (2):

$$
U=U_{0}-C^{T} Z_{b} C U S=\left[\begin{array}{l}
10.302-j 0.066 \\
10.085-j 0.138 \\
9.87-j 0.209 \\
9.633-j 0.285 \\
9.53-j 0.318 \\
9.444-j 0.347 \\
9.371-j 0.373 \\
9.346-j 0.382
\end{array}\right] \mathrm{kV}
$$

It can be seen from the calculations that the node voltage deviations are within the permissible limits only for the first five nodes. In order to check the developed algorithms, we determine the values of the required CP capacities from the position of synthesis of the mode by voltage. Suppose the desired node voltage values are given by: $\mathrm{U}_{1 \mathrm{~d}}=10.325 \mathrm{kV}, \mathrm{U}_{2 \mathrm{~d}}=10.136 \mathrm{kV}, \mathrm{U}_{3 \mathrm{~d}}=9.953 \mathrm{kV}$, $\mathrm{U}_{4 \mathrm{~d}}=9.758 \mathrm{kV}, \mathrm{U}_{5 \mathrm{~d}}=9.679 \mathrm{kV}, \mathrm{U}_{6 \mathrm{~d}}=9.618 \mathrm{kV}, \mathrm{U}_{7 \mathrm{~d}}=9.582$ $\mathrm{kV}, \mathrm{U}_{8 \mathrm{~d}}=9.58 \mathrm{kV}$ and it is necessary to find the power of the compensating devices providing the predetermined mode.

Having solved the system of equations (9), we determine the compensating devices powers, which are equal to:

$$
Q_{C D}=\left[\begin{array}{l}
0.075 \\
0.069 \\
0.074 \\
-0.148 \\
0.319 \\
0.12 \\
0.005 \\
-0.144
\end{array}\right] \text { MVAr }
$$

Installation of the compensating devices with the capacities defined above shall provide the desired values of the node voltages. In order to check the correctness of the $\mathrm{CP}$ power determination, we will calculate the voltage mode taking into account the reactive powers of the compensating devices according to formula (2).

The calculations confirm the efficiency of the topological algorithm in determining the necessary capacities of compensating devices to provide the desired voltages in the nodes of distribution networks.

\section{Conclusion}

1. A topological method for calculating the power of compensating devices from the position of synthesis of modes by voltage has been developed.

2. The developed algorithm can be used to determine the location and type of CS installation to provide the desired voltage level.

\section{References}

1. A. Mecke, I. Lee, J.R. Baker jr., M.M. Banaszak Holl, B.G. Orr, Eur. Phys. J. E 14, 7 (2004)

2. M. Ben Rabha, M.F. Boujmil, M. Saadoun, B. Bessaïs, Eur. Phys. J. Appl. Phys. (to be published)

3. Luigi T. De Luca, Propulsion physics (EDP Sciences, Les Ulis, 2009)

4. F. De Lillo, F. Cecconi, G. Lacorata, A. Vulpiani, EPL, 84 (2008)

5. Instructions for reactive power compensation in distribution networks. VNIIE.M: Energy, 1974, -73 s.

6. Arkhipov N.K. Voltage mode in electrical distribution networks. M.: VZEI publishing house, 1964.-131s.

7. GOST 13109-97. Electric power. Compatibility of technical means is electromagnetic. Standards of electric power quality in general-purpose power supply systems. M.: Gossandart, 1998. -32 p.

8. Zhelezko Yu.S. Determination of power and places of local voltage control installation//Electrical stations. Moscow. 1972.- No. 11.- C.34-36.

9. Barkan J.D. Automation of voltage control in distribution networks. M.: Energy, 1972.-120s.

10. Zhelezko Yu.S. Loss of Electricity. Reactive power. Quality of electricity. M.: Publishing House of NC ENAS, 2009.-420s.

11. Geraskin O.T. Graphs of the electric network and topological formulas//Izvestia of the USSR Academy of Sciences. Energy and Transport. 171.- No. 4C.66-75.

12. Dauren S. Akhmetbayev, Daurenbek A. Aubakir, YermekZh. Sarsikeyev,Bakhtybek A. Bainiyazov ,Mikhail A. Surkov, Vitaliy I. Rozhko, Gulbahit N. Ansabekova, Assel S. Yerbolova, Azamat T. Suleimenov, Miramgul S. Tokasheva. Development of topological method for calculating current distribution coefficients in complex power networks, // Results in Physics, 2017, 7, стр.,1644-1649. 
13. Dzhandigulov A.R., Akhmetbaev D.S. Implementation of a new topological algorithm for calculating current distribution coefficients in complex electrical networks. Software for computers. Certificate of Entry of Information into the State Register of Rights to Copyrighted Objects No. 1552 dated January 31, 2019.

14. Dzhandigulov A.R., Akhmetbaev D.S. Finding all the core graphs of a given graph. Software for computers. Certificate of Entry of Information into the State Register of Rights to Copyrighted Objects No. 1551 dated January 31, 2019.

15. DaurenAkhmetbayev, Arman Akhmetbayev, Azamat Suleymenov, Michal Kolcun .Modeling the Set Mode of Complex Power Grid,Based on Infeed Coefficients// Proceedings of the 9th International Scientific Symposium/Elektroenergetika 2017, 12.14. 9. 2017, StaráLesná, Slovak Republic.

16. D.S. Akhmetbaev, A.R. Dzhandigulov, A.D. Akhmetbaev.Topological algorithm for forming nodal stresses of complex networks energy systems. WebofConferences139, 01066(2019)

17. D.S. Akhmetbaev ; A.D. Akhmetbaev ; A.R. Dzhandigulov. New Approachesto the Topological Method of Analysis of Electrical Networks. International Multi-Conference on Industrial Engineering and Modern Technologies, FarEastCon, 2019.

18. D.S. Akhmetbaev, A.R. Dzhandigulov,A.D. Akhmetbaev. Topological algorithm forforming nodal stresses ofcomplex networks energy systems. E3S WebofConferences 139, 01066 (2019).

19. Akhmetbayev D., Akhmetbayev A.,Aidarova A. Determination of rationaltransformation coefficients transformers distribution networks//E3S Web of conferences 25.04003 (2018)

20. Akhmetbaev D.S., Dzhandigulov A.R. Development of algorithms for a new topological method for calculating current distribution coefficients in complex electrical networks//eurasian journal of mathematical and computer applications. ISSN 2306-6172, Volume 7, Issue 3 (2019 ) 4 - 12

21. Development of algorithms for the formation of steady-state modes based on the topology of electric power systems// Journal of Physics: Conference Series 1392(1), 012079, 2019. 